\title{
Construyendo lo contemporáneo. Apuntes acerca de la creación de una imagen de contemporaneidad en arteBA
}

\section{Artículo de reflexión}

\author{
Jonathan Feldman \\ CONICET-UNTREF, UNA. Argentina \\ jonfeld@gmail.com \\ Recibido: 26 de febrero de 2021 \\ Aceptado: 30 de mayo de 2021
}

Como citar este artículo: Feldman, Jonathan (2022). Construyendo lo contemporáneo. Apuntes acerca de la creación de una imagen de contemporaneidad en arteBA. Calle14: revista de investigación en el campo del arte. 17(31), pp. 114-131.

DOI: https://doi.org/10.14483/21450706.18703

\section{Agradecimientos y naturaleza del escrito}

Este artículo de reflexión forma parte de los resultados obtenidos en mi investigación doctoral, que me encuentro realizando en la Universidad Nacional de Tres de Febrero con la ayuda de una beca otorgada por CONICET. Agradezco la colaboración de las autoridades universitarias y del directorio de CONICET tanto para la obtención de fondos como para el acceso a material de archivo. Quisiera agradecer también a mi directora de tesis, Dra. Talia Bermejo, por su constante guía, y a todos los entrevistados y trabajadores de archivos que contribuyeron a su realización.

\section{(c) (i)}

https://creativecommons.org/licenses/by/4.0/deed.es 



\begin{abstract}
Resumen
El presente artículo tiene por objetivo analizar la feria arteBA, que se realiza anualmente desde 1991 en Buenos Aires, Se estudiará su mirada sobre el arte contemporáneo y su lugar dentro del campo artístico local e internacional. Se tomarán en cuenta algunas de sus acciones y dimensiones organizativas para trabajar nociones vinculadas a la construcción de una imagen de contemporaneidad bajo la mirada hegemónica del sistema de circulación artística global. En este sentido, se trabajará bajo el supuesto de un funcionamiento reticular del campo, que condiciona el lugar de arteBA como agente de legitimación del arte.
\end{abstract}

\title{
Palabras clave
}

Arte contemporáneo; arteBA; hegemonía; retroalimentación

"Building the contemporary". Notes on the creation of an image of contemporaneity in arteBA

\begin{abstract}
The purpose of this article is to analyze the arteBA fair, which has been held annually since 1991 in Buenos Aires. We will study its view on contemporary art and its place within the local and international artistic field. Some of its actions and organizational dimensions will be taken into account to work on notions related to the construction of an image of contemporaneity under the hegemonic gaze of the global artistic circulation system. In this sense, we will work under the assumption of a reticular operation of the field, which conditions the place of arteBA as an agent of legitimation of art.
\end{abstract}

\section{Keywords}

Contemporary art; arteBA; hegemony; feedback

«Construire le contemporain ». Notes sur la création d'une image de contemporanéité dans arteBA

\begin{abstract}
Résumé
Le but de cet article est d'analyser la foire arteBA, qui se tient chaque année depuis 1991 à Buenos Aires. Nous étudierons son regard sur l'art contemporain et sa place dans le champ artistique local et international. Certaines de ses actions et dimensions organisationnelles seront prises en compte pour travailler sur des notions liées à la construction d'une image de contemporanéité sous le regard hégémonique du système de circulation artistique global. En ce sens, nous travaillerons sous l'hypothèse d'un fonctionnement réticulaire du champ, qui conditionne la place d'arteBA comme agent de légitimation de l'art.
\end{abstract}

\section{Mots clés}

Art contemporain ; arteBA ; hégémonie ; retour d'information

Construindo o contemporâneo. Notas sobre a criação de uma imagem de contemporaneidade em arteBA

\section{Resumo}

O presente manuscrito tem por objetivo analisar a feira arteBA que se realiza anualmente desde 1991 em Buenos Aires. Se estudará seu olhar sobre a arte contemporânea e seu lugar dentro do campo artístico local e internacional. Se levará em conta algumas de suas ações e dimensões organizativas para trabalhar noções vinculadas com a construção de uma imagem de contemporaneidade sob o olhar hegemônico do sistema de circulação artístico global. Neste 
sentido, se trabalhará sob o suposto de um funcionamento reticular do campo, que condiciona o lugar de arteBA como agente de legitimação da arte.

\section{Palavras chave}

arteBA- contemporâneo; hegemonia; retroalimentação

Rurakuna kaiarii Sugllapi kawangapa apangapa kiwa chiurralla apangapa kachangapa chiura ArteBA sutipi

\section{Maillallachiska}

Kai makiwa kilkaskapi munaku iuiachinga imasami rurankuna kai Arteba sutipi, apachikuna wata watapi kai 1991 wata kauramandata Buenos Aires suti Llagtapi kaipiiachai kungapkankuna kawaspa ñugpata kaska chasa kawachingapa nukanchita chasallata kanchasinama, kawangap kankuna imasami paikuna allilla rura tukuikunata kawachingapa. Chimanda kaipi Munanaku churangapa ukunimandata, apangapa arteba sutipi ruraskata allilla awapi sakingapa.

\section{Rimangapa Ministidukuna}

ArteBA; Ruraikunata kawachingapa; chi watallapi ruraska nuka munaska rurai; chillatata chillapita 


\section{Presentación}

El presente trabajo analiza la construcción de la categoría de lo contemporáneo en la feria arteBA desde su creación hasta 2016, a partir de tres presupuestos: el primero, que los dispositivos de exhibición -entre los que se encuentran las ferias de arte- conforman identidades y representaciones sociales a partir de programas específicos (Staniszewski, 2001); el segundo, que las ferias de arte (y los museos en cierto grado) han atravesado ciertos procesos que se podrían denominar de bienalización (Sassatelli, 2009) que las acercan al desarrollo de eventos como las bienales en cuanto a su despliegue, el vínculo con el desarrollo urbano (Millán Valdés, 2009), entre otros elementos; el tercero indica que el campo del arte contemporáneo se caracteriza por un funcionamiento reticular y retroalimentativo entre sus agencias, entre las que se incluye el mercado, a escala global expandida respecto de otros momentos (Moulin, 2012; Graw, 2013).

La hipótesis de este texto es que arteBA construye su imagen de contemporaneidad en base a estructuras, estrategias y puntos de vista que son hegemónicos en la escena global. Entre ellos se puede mencionar la convocatoria a agentes como curadores, historiadores o críticos como sostén de la "seriedad" de la feria; ciertas estrategias para atraer compradores y coleccionistas internacionales a través de las propuestas de arte emergente sin resignar la oferta de artistas consagrados; la propuesta de la feria como evento destacado de la vida cultural urbana; y la incorporación de artistas con circulación simultánea por espacios de formación y exhibición de relevancia.

Así, el trabajo caracterizará aquellas acciones llevadas adelante por arteBA para posicionarse como una feria de arte contemporáneo internacional que da impulso a ciertos artistas y obras a la escena global. Se trabajará el modo en que arteBA produce un viraje en su mirada respecto del arte contemporáneo, que lleva de un primer momento de emergencia e institucionalización (primera década de arteBA) a reemplazar la denominación de "feria de galerías" por "feria de arte contemporáneo" en 2003, y que a partir de ese momento instituye un programa con fuerte incidencia de la mirada curatorial para consolidar su imagen de contemporaneidad, coronada por los festejos del vigésimo quinto aniversario, la edición especial de 2016.

\section{Lo contemporáneo en arteBA}

La Fundación arteBA se creó en 1989, en sincronía al comienzo del gobierno de Carlos Menem, que propondría un proyecto alineado con el denominado Consenso de Washington respecto de metas fiscales, desregulaciones financieras y flexibilización laboral, entre otras cuestiones. En un contexto de expansión y recuperación económica primera - cuya contracara, como se sabría más adelante, fue una caída generalizada del nivel de vida, combinada con un gran incremento de la brecha entre las clases pudientes y las carenciadasse presentó la oportunidad para imaginar una feria de arte en Buenos Aires.

Carlos Grosso, intendente de la Ciudad de Buenos Aires entre 1989 y 1992, junto al el ex secretario de Obras Públicas y fundador, Jacobo Fiterman, habló con Ruth Benzacar y otros galeristas para proponerles una feria. Grosso, quien entendió los beneficios que podría traer en materia de circulación cultural, aceptó una reunión:

"Posiblemente el origen de arteBA haya estado en el CC Recoleta. Estábamos Diana Saiegh, Alejandro y yo. Hicimos el décimo aniversario y se nos ocurrió hacer cosas distintas. Hicimos una muestra de la Nueva Figuración, y allí creamos un vínculo muy fuerte con Grosso.

Lo fui a ver [Grosso] [...] Me preguntó: ¿aceptás el desafío? Y le puse una sola condición: necesitaba cien mil dólares. Si yo no hacía una cosa, digamos, espectacular, de alto nivel, no iba a ningún lado". ${ }^{1}$

La propuesta tomó como referencia a la entonces novedosa ARCO Madrid, que había impulsado un gran dinamismo en la circulación del arte español, y estaba encaminada a lograr una gran visibilidad internacional. El modelo de ARCO comprendía un estado provincial involucrado con el proyecto artístico, que aportaba recursos y con un contenido que superaba la compra-venta de arte y que involucraba una noción de expansión cultural. arteBA, por su parte, se propuso exceder la instancia mercantil para "situarse como un referente cultural de Latinoamérica".2

Sin embargo, para poder atraer más galerías y constituirse como referente cultural a nivel internacional,

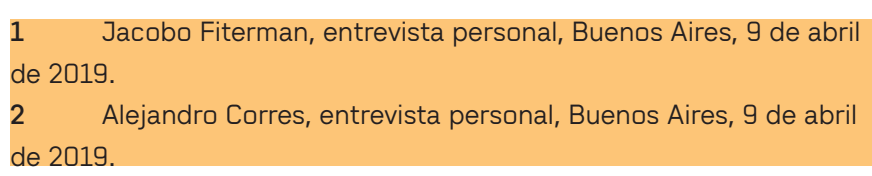




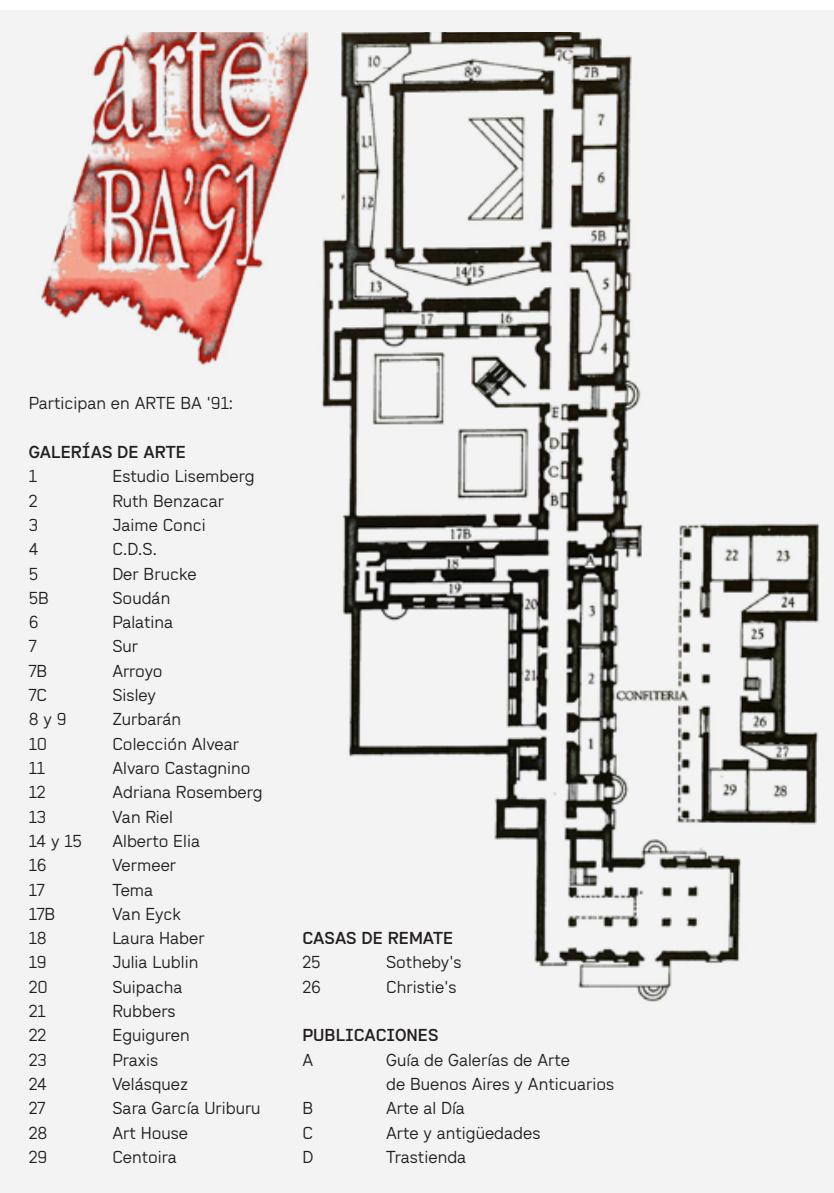

arteBA debía, primero, demostrar calidad (en cuanto a su visualidad, pero también respecto a su sostén académico) y segundo, incorporar artistas con gran circulación por otros espacios. En este sentido, este trabajo propone que tanto lo primero como lo segundo permitieron a arteBA, en especial luego de su transformación como "feria de arte contemporáneo" en 2003, construir su imagen de contemporaneidad.

Así, y antes de abordar las dos necesidades recién planteadas, es pertinente referirse a aquello que se denomina "arte contemporáneo" para poder dar cuenta de lo que significa en una feria adoptar esa denominación. Existen numerosas definiciones y periodizaciones del arte contemporáneo. Alexander Alberro (2011), por ejemplo, afirma que su aparición coincide con la reconfiguración mundial que produjo la caída del muro de Berlín en 1989, y que por lo tanto el arte contemporáneo como fenómeno debe ser visto en su contexto de nacimiento: la era de la globalización. Terry Smith (2012), por su parte, despliega un análisis respecto del lugar no universalista, más relativo que generalizador, del arte contemporáneo: “[...] hoy el arte se produce, tal vez como nunca antes, en el marco de una sensación
Figura 1. Planta arteBA 1991. Fuente: Catálogo arteBA.

ampliamente compartida de que la difusión y la contingencia son lo único que existe [...]" (Smith 2012, p.16).

Para Boris Groys $(2009$, 2014) el arte contemporáneo es aquel que se produce en la inmediatez del ahora, que ofrece una experiencia del presente. El autor indica que la duda, la indecisión, así como la continua reescritura del pasado y del futuro, son características de la contemporaneidad y su arte, e incluso propone como síntoma el cada vez mayor número de exhibiciones temporales en reemplazo de mostrar las colecciones de los museos. A su vez, realiza una mirada de la escena del arte contemporáneo y encuentra que muchas producciones tienen una base temporal, y que tematizan respecto del tiempo no productivo, no histórico. En ese sentido, existe un exceso de tiempo que permite la operación de la repetición, y es esa repetición la que inicia, a través del arte, una ruptura en la continuidad de la vida.

Desde otra mirada, Georges Didi-Huberman (2015) define la noción de anacronismo como habilitante de una manera de considerar la historia del arte desde una perspectiva no lineal o progresiva, sino más bien discontinua. Este anacronismo es observable, para el 


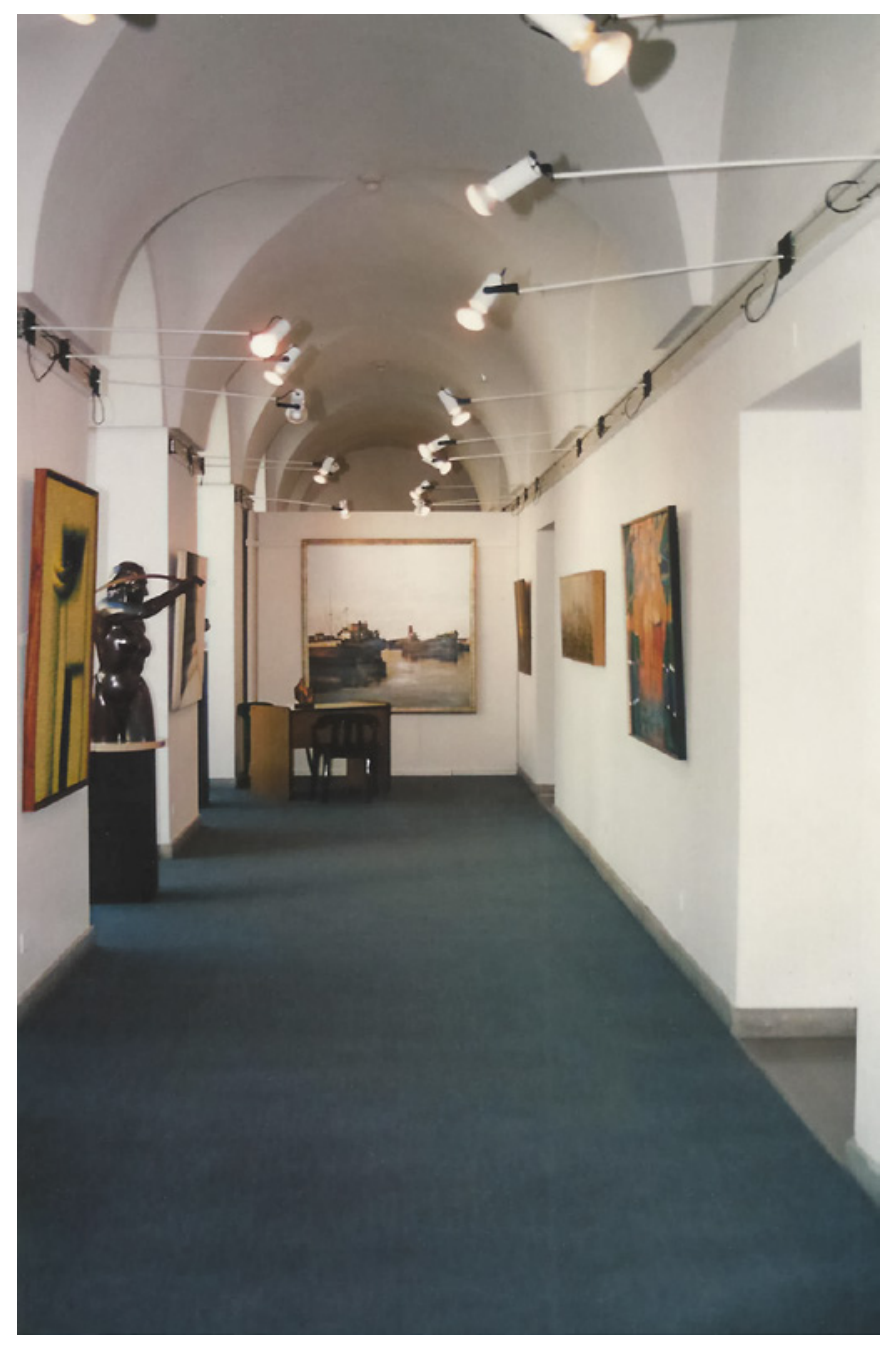

autor, en una multiplicidad de temporalidades que son condición del hacer histórico, y son propias del encuentro con las imágenes, pues en ellas el presente está en continua reconfiguración. Afirma que solamente existe historia de los síntomas, y que esta apertura permite la inclusión de cierta complejidad que hace visibles zonas heterogéneas de la historia, que permite una visión dialéctica y contingente, recursiva. También Giorgio Agamben (2008) se refiere a lo contemporáneo, aunque en un sentido más general y con una visión nostálgica “... esa relación singular con el propio tiempo, que se adhiere a él pero, a la vez, toma distancia de éste; más específicamente, ella es esa relación con el tiempo que se adhiere a él a través de un desfase y un anacronismo" (Agamben, 2008, p. 1)

Estas posiciones se encuentran analizadas por Claire Bishop en Museología radical (2018), quien las ubica dentro de dos grupos que o bien miran a lo contemporáneo como estasis, deriva de la era poshistórica, o bien como una modificación en los vínculos, más plurales y disyuntivos, con el tiempo. La autora toma esta última
Figura 2. Vista interior del stand de galería Soudan en arteBA 1994. Fuente: Archivo Fundación arteBA.

propuesta y agrega la necesidad de una perspectiva que tome en cuenta la diversidad y especificidad del tiempo y el contexto para posicionarse de manera crítica y política y ofrecer alternativas a ciertas estructuras de poder de cara al futuro.

En este sentido, y desde una perspectiva más local, Andrea Giunta (2014) analiza la aparición de síntomas de lo contemporáneo en el arte argentino y latinoamericano y lo ubica en algunas obras de la década del sesenta. La autora defiende una posición de análisis que descompone la lógica centro-periferia, y por ende analiza la aparición de "vanguardias simultáneas" (obras que se insertan en la lógica global pero que activan situaciones específicas) y movimientos pioneros del arte contemporáneo. Giunta y Alberro coinciden en señalar el impacto que produjo la tecnología —en especial la aparición de internet- en el campo de las artes, y también en ciertas características como la multiplicidad temporal o la falta de dominancia estilística. Sin embargo, la propuesta de Giunta se relaciona más con la de Bishop en tanto ambas miran el rol del arte 
contemporáneo desde su lugar de afectación del futuro en una determinada sociedad, es decir, desde su función política como modificador de ciertas realidades.

Como se verá en los próximos párrafos, la imagen que construye arteBA tiene componentes que se pueden relacionar tanto con las visiones pesimistas que afirman lo contemporáneo en las ferias de arte como una estrategia de marketing para incrementar la demanda y ventas, como con aquellas que intentan dejar una marca que proponga reflexiones en torno al lugar del arte como fenómeno social.

En referencia a la calidad de la feria, las primeras ediciones de arteBA tuvieron ciertas características de amateurismo en cuanto a su montaje, a las propuestas de las galerías, a la selección de participantes, entre otros. La escasez de espacio y la proximidad de las galerías lograron que las paredes estuviesen cubiertas casi en su totalidad, de algún modo emulando la estética de las galerías comerciales. La simpleza en la organización también se tradujo en el interior de los estands, que según los organizadores tenía “... una estética de colgado, hay una tendencia de montar todo apretado, y el montaje es clave [...] había una gran diferencia en el montaje entre las galerías de afuera y las locales...".3

A partir de la mudanza primero al Centro de Exposiciones y luego a La Rural, se modificaron las estructuras por estands transportables que se arman y desarman, se trabajaron elementos como los sistemas lumínicos para lograr una ambientación diferenciada, se adquirió un criterio de selección basado en las propuestas de las galerías, y se comenzaron a agregar más y más espacios especiales y curados para funcionar como proyectos complementarios a la exposición de galerías.

Con respecto a esto último, la curaduría como operación privilegiada ingresó en la feria de manera temprana, con proyectos como el Patio de Esculturas (curado en todas sus ediciones por Nelly Perazzo), las secciones de grabado (Bienal a partir de 1997) o algunas propuestas de arte actual (como la exhibición en arteBA 1995 organizada por Jorge López Anaya). Pero, tomaron mayor relevancia a partir de 1998 y, en mayor medida incluso, a partir de 2003. Si se observa, este ascenso de lo curatorial coincide con la conformación de la práctica como una profesión a nivel mundial

3 Julia Coverti, entrevista personal, Buenos Aires, 6 de febrero de 2019. a lo largo de la década del noventa y principios de dos mil, cuando la figura del curador cimienta su posición como agente de legitimación de las artes reemplazando a otros actores como los críticos y simultáneamente se consolidan cada vez más programas de formación profesional en curaduría.

Entre los proyectos especiales de arteBA se quieren destacar las experiencias de "U-Turn", "Cabinet" y "Dixit", que se zonificaron para mantenerlos integrados y simultáneamente diferenciados de los estands de galerías. "U-Turn" comenzó en 2011 como parte de los festejos del vigésimo aniversario de la feria, cuando se convocó a galerías de Alemania, Brasil, México, Colombia y Argentina para trabajar en una propuesta que tomara en cuenta la dimensión espacial del arte y su relación con otros aspectos de la vida. La propuesta, curada por la iraní-norteamericana Abaseh Mirvali, permitía por un lado una incorporación de formatos diversos ligados a exposiciones temporales y, además, atendía al fenómeno de bienalización que se identificó anteriormente como dominante a nivel global: "Este lugar ostenta una estética conceptual que lo diferencia del resto de la feria y trae los aires del mainstream internacional" (Martínez Quijano, 2011, s/p). En sus ediciones posteriores participaron, además de la propia Mirvali, curadores como Agustín Pérez Rubio (2014) y Jacopo Crivelli Visconti (2015 y 2016). Además de los problemas antes mencionados se trabajaron cuestiones vinculadas a la exhibición de una feria como si fuese una muestra en un museo, la historia, el tiempo, el lenguaje y la comunicación (es decir, la inscripción histórica del arte contemporáneo y las cuestiones geopolíticas que relacionan a América Latina con Europa y Estados Unidos), la relación entre las palabras y las cosas (tomando como punto de partida el famoso texto de Michel Foucault), el lugar de la feria como democrático frente a la imposición dictatorial del international style curating y los vínculos que surgen en la yuxtaposición de las obras cuando no se toma un tema como guía sino que se permite que las producciones sean las que presenten sus relaciones.

"Cabinet", que se presentó como un espacio dentro de algunas galerías de la sección principal, en los cuales se destacan una o más obras de sus artistas, pretendía construir series de obras "relevantes, de carácter museístico" que eran seleccionadas por un comité especial (el primero compuesto por Sonia Becce, Victoria Noorthoorn y José Roca) y formaban parte de los propios estands de las galerías participantes. La diferencia con "U-Turn" radica en que, si bien también 
es una sección curada y con similitudes en los modos de exhibición de museos, las galerías no son invitadas, sino que abonan un extra para obtener su cabinet (gabinete). Esto lo liga más al aparato comercial que "U-Turn" al reivindicar la centralidad de las galerías como motores de la feria. Como se verá, también posee diferencias con "Dixit", que en este sentido es más semejante a "U-Turn" que a "Cabinet". Sin embargo, hay otro componente que se vincula a la construcción de ciertas líneas historiográficas con artistas consagrados y más contemporáneos.

“Dixit", por su parte se presentó de la siguiente manera: "Un curador invitado organiza una exhibición en la feria a partir de una hipótesis propia que trabaja sobre la contemporaneidad artística. Esta sección ofrece obras de artistas a museos y colecciones particulares, a través de sus galerías" (arteBA 2014, p. 177). Es decir que, algo que sucedía en efecto en otras secciones se anunció en esta como una innovación que, al mismo tiempo, enunciaba su objetivo comercial al resaltar la oferta de obras a instituciones y coleccionistas privados. Las dos ediciones más destacables fueron la de 2014 y la de 2016, curadas por Andrea Giunta y Lara Mármor, Federico Baeza y Sebastián Vidal Mackinson, respectivamente.

La primera dio lugar a la publicación ya mencionada de Giunta (2014) en la que se preguntaba sobre el carácter contemporáneo de ciertas producciones y hacía un recorrido historiográfico por obras de artistas de Argentina, Bolivia, Brasil, Chile, Colombia, México, Perú, Puerto Rico y Uruguay. Esta propuesta planteaba la necesidad de construir una historiografía argentina y latinoamericana con el eje puesto en la alteridad proveniente del Sur, sin ofrecerla en contraste al arte europeo o norteamericano. Además, tiene un especial carácter museal retrospectivo, con gran cantidad de obras y artistas participantes, y presentado como un panorama de la historia del arte argentino. De manera que no solamente se integra lo contemporáneo desde el punto de vista de los participantes, sino que se discuten las posiciones que identifican en el arte contemporáneo visiones plausibles de contradicciones, anacronismos y contingencias, atendiendo a nociones de contemporaneidad que se relacionan a lo afirmado por Smith y Groys, por ejemplo. Por supuesto, la imagen de contemporaneidad era explícita en tanto la exhibición se planteaba la pregunta respecto del nacimiento del arte contemporáneo, y a diferencia de Alberro ubicaba su aparición a partir de la década del sesenta.

En 2016 se presentó la exposición "Oasis", cuyo objetivo era ofrecer como parte de los festejos del vigésimo quinto aniversario de arteBA, un panorama del arte contemporáneo desde los noventa en adelante, con la condición de que las obras debían provenir de artistas cuyas galerías participaran en 2016 de la feria. Los curadores se preguntaban si el arte contemporáneo

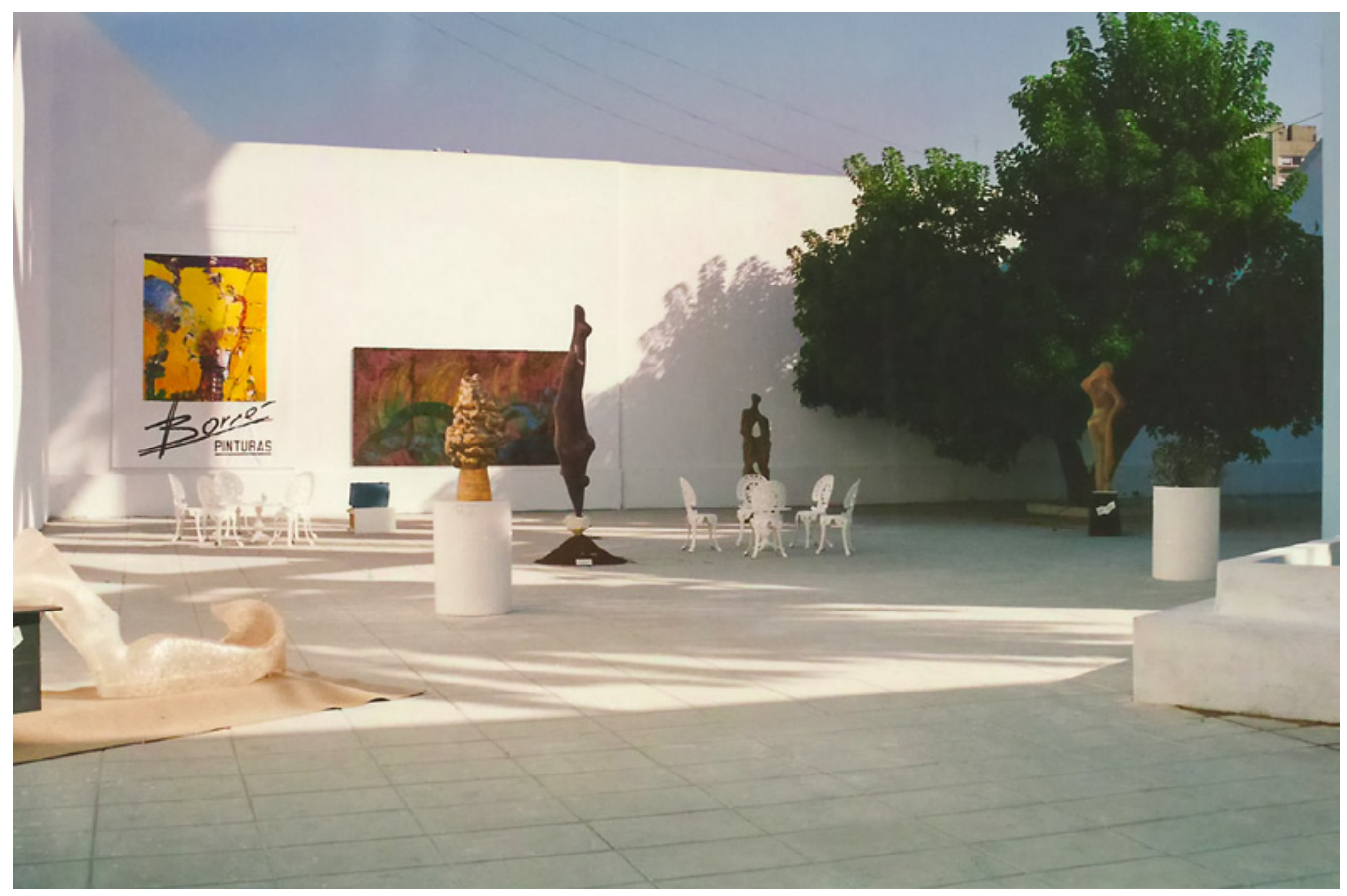

Figura 3. Patio de esculturas en arteBA 1995. Curaduría de Nelly Perazzo. Fuente: Archivo Fundación arteBA. 


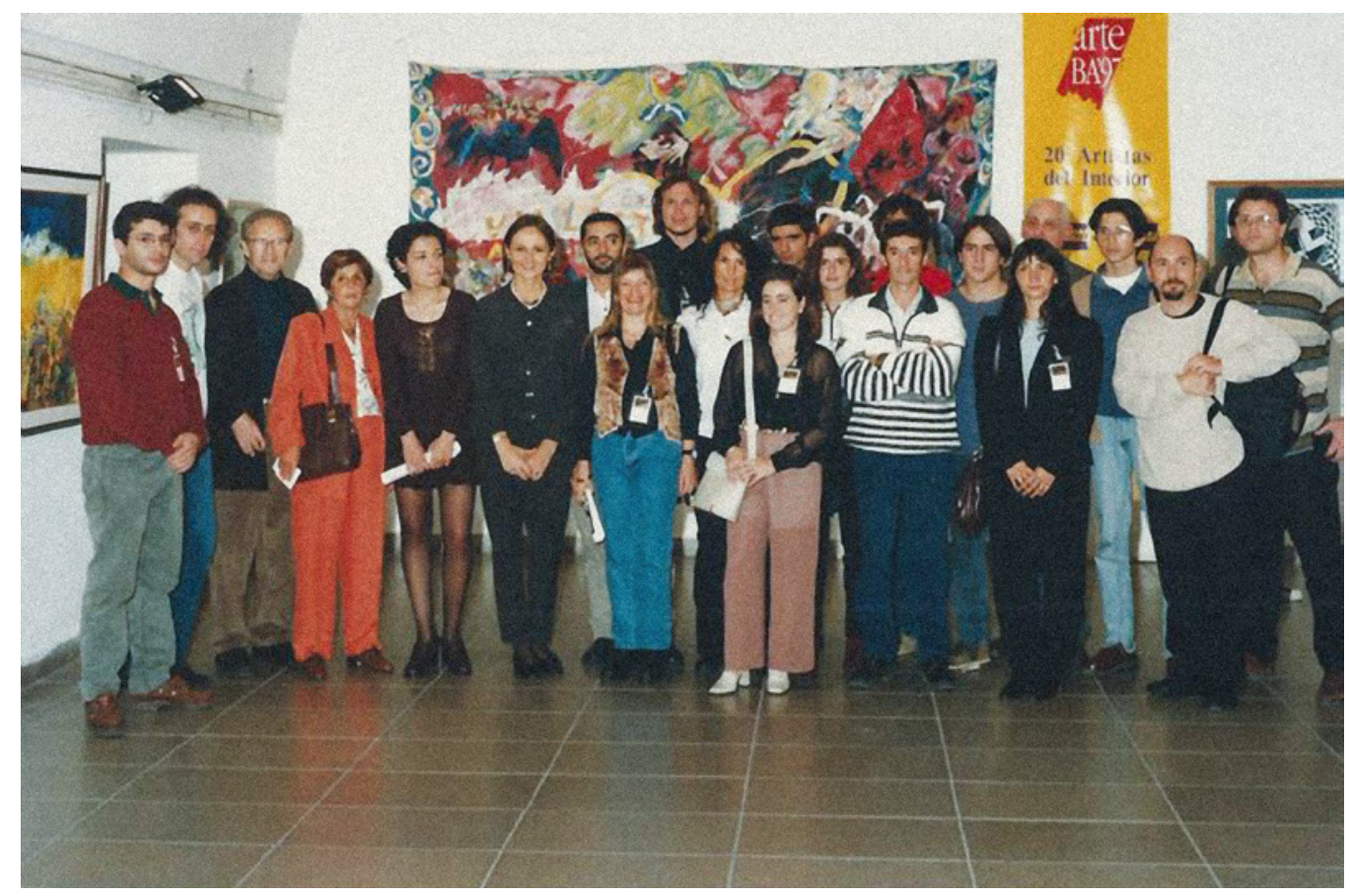

Figura 4. Exposición "20 artistas del interior" en arteBA 1997. Jacobo Fiterman (presidente arteBA) y Teresa de Anchorena (directora del CCR) con los seleccionados para el certamen: Víctor Javier Basaldúa, José Leandro Giménez, Claudio Osan, Edgardo Beltrán Saluzzio, Diego Sierro, Ana María Zaball, Claudia Patricia San Martín, Nelson Abel Branly Baylac, Mariana Buchin, Mabel Burel, Pedro Hugo Cava, Raúl D`Amelio, Ana Fabry, Geraldhyne Fernández de Gasparotti, Gabriela Pertovt, Marcelo Villega, Andrés Bancalari, Diego Figueroa, Alejandro Mahave y Marina Muñoz. Fuente: Archivo Fundación arteBA.

argentino podía definirse a partir de una condición insular respecto de las producciones y la circulación global. En un ejercicio que tomaba prestadas ciertas nociones puestas en espacio por Lina Bo Bardi, la muestra intentó recuperar el interrogante acerca de las narrativas del arte local y su vínculo con la imagen hegemónicamente creada de América Latina y su arte. El resultado fue visualmente asimilado al concepto que le dio lugar, de modo que al ingresar se circulaba por zonas que parecían desligadas y, en conjunto, brindaban una visión general pero heterogénea del arte argentino de los últimos tiempos. ${ }^{4}$ La contemporaneidad de la propuesta estaba dada tanto por los artistas

4 Los artistas convocados fueron Nicanor Aráoz, Gabriel Baggio, Javier Barilaro, Diego Bianchi, Jane Brodie, Eugenia Calvo, Laura Códea, Claudia Del Río, Valentín Demarco, Lucas Di Pascuale, Zoe Di Rienzo, Matías Duville, Víctor Florido, Marcelo Galindo, Sebastián Gordín, Vicente Grondona, Jorge Gumier Maier, Carlos Huffmann, Pablo Insaurralde, Guillermo Iuso, Daniel Joglar, Fabio Kacero, Irinia Kirchuk, Fernanda Laguna, Nani Lamarque, José Luis Landet, Valentina Liernur, Lux Lindner, Lucrecia Lionti, Gustavo Marrone, Miguel Mitlag, Leticia Obeid, Marcelo Pombo, Déborah Pruden, Juan Carlos Romero, Rosa Chancho, Pablo Rosales, Daniel Santoro, Mariela Scafati, Cristina Schiavi, Rosana Schoijett, Marcela Sinclair, Juan Stoppani, Axel Straschnoy, Eduardo Stupía, Mariana Tellería, Trulala, Leila Tschopp, Nahuel Vecino Adrián Villar Rojas y Román Vitali. como por la visión de insularidad por la cual se interrogaba la exhibición.

El hecho de que se incluyera como parte del programa de una feria y que participaran artistas de las galerías expuestas implicaba un movimiento estratégico en relación con el, debido a que daba cuenta del lugar de arteBA como proveedor de tendencias emergentes $y$, simultáneamente, como constructor de representaciones de localidad que jugaran en la escena internacional.

En este sentido, las miradas estaban más puestas sobre la presentación de lo local por fuera de la lógica que las convierte en versiones desfasadas de arte europeo o americano, para dar cuenta de las contingencias en la historiografía, por ejemplo argentina, y echar luz sobre zonas oscurecidas de la historia del arte. Por ello, se parecen más a la propuesta de Bishop respecto de la función política del arte contemporáneo que a visiones más pesimistas ${ }^{5}$. Sin embargo, es claro que arteBA está lejos de comportarse como uno de los

$5 \quad$ En este último sentido se pueden entender posiciones como la de Danto o Smith, que caracterizan el arte contemporáneo a partir de la heterogeneidad de formas de producción y las relacionan con el fin de los grandes relatos o un vínculo temporal múltiple situado 


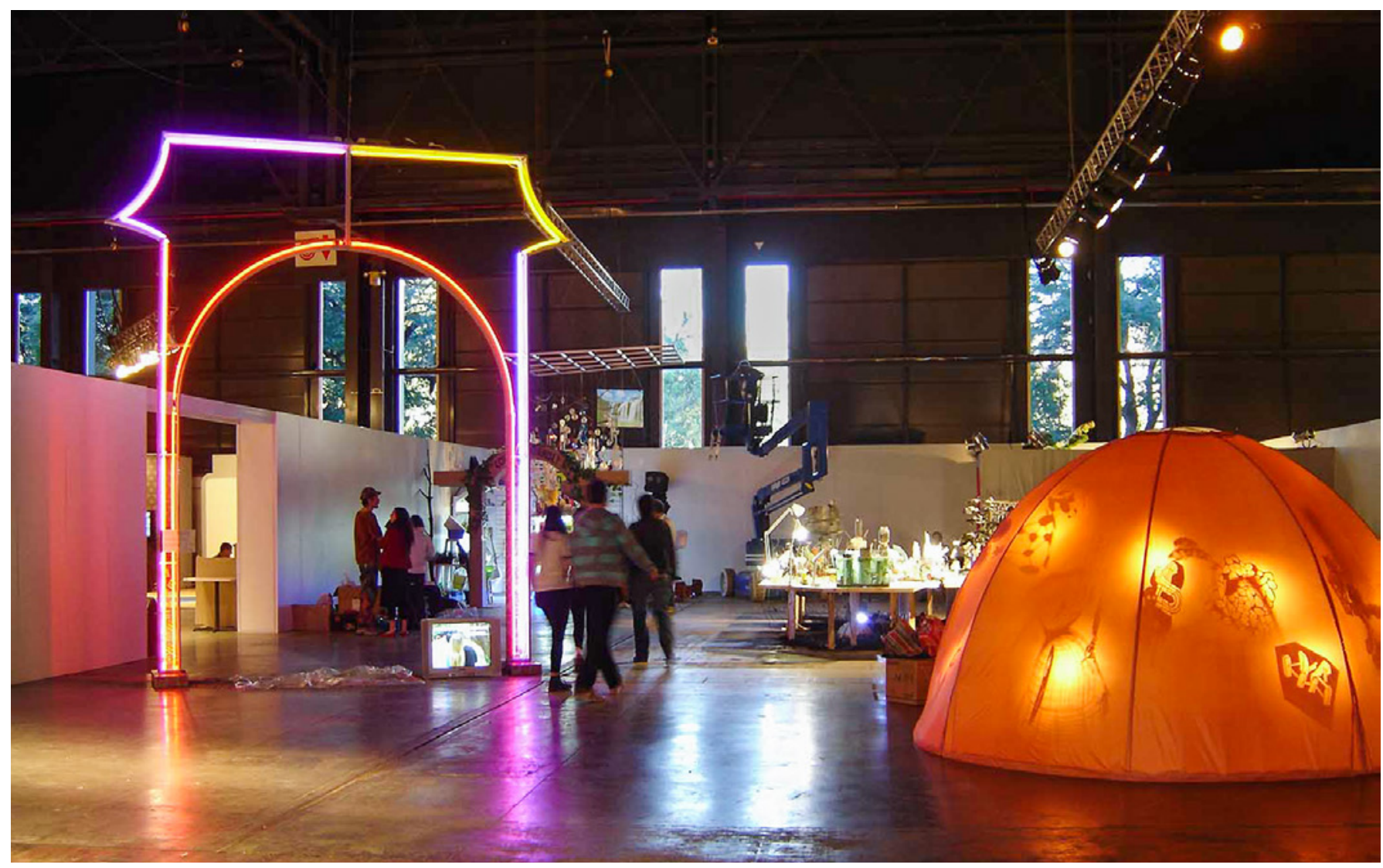

Figura 5. Premio Petrobras-arteBA 200. (de izq. a der.) "Mejor beso" (Leonardo Mercado, 2007), "Wikipedia” (Diego Bianchi, 2007), “Pedazos de la persona que amamos" (Adrián Villar Rojas, 2007) y "Teatro de guirnaldas / La rebelión de los artefactos" (Julia Masvernat, 2007). Fuente: Archivo Fundación arteBA.

museos descentrados que propone la autora, como Van Abbemuseum de Eindhoven o el MSUM de Liubliana, que retan la división centro-periferia al implementar programas que recuperan las especificidades de sus países y ofrecen alternativas al modelo global, con limitaciones, por supuesto.

En relación con la incorporación de artistas del momento, algo notorio que es que, si bien existe sincronía entre los artistas que circulan por arteBA y aquellos exhibidos en otros espacios, entre 1991 y 1997 la incorporación de artistas del momento a la feria tuvo cierto desfase, y hubo una mayor concentración en ofertas más tradicionales y de artistas de los ochenta. En arteBA, los nombres de artistas de las generaciones de fines de los ochenta y los noventa habían tomado parte de la escena, tímidamente a partir del 1995, y con gran fuerza luego de 1997. Entre 1998 y 2000, en cambio, se produjo una gran participación de artistas de las corrientes más importantes, y movimientos hacia el arte

en la contemporaneidad como nexo entre pasado y futuro (sin programas teleológicos como la modernidad o revisionistas como la posmodernidad). emergente que se comenzaría a mostrar con más fuerza hasta alcanzar su punto más alto a partir de 2003 y, en particular, desde la creación del Barrio Joven en 2005.

Por ejemplo, en 1995 Annina Nosei presentó por primera vez en arteBA obra conceptual de Guillermo Kuitca, CML-Hilda Solano y Ruth Benzacar llevaron obra de Alfredo Prior, Adriana Indik incluyó algunas piezas conceptuales de Susana Beibe y Marina Nogueira, de Lily Wicnudel. Los nombres de Jorge Macchi gran referente del neo-conceptualismo local-, Juan Paparella, Rosana Fuertes o Nicola Costantino aparecen por primera vez entre 1996 y 1998 en la galería Ruth Benzcar junto a artistas del Rojas como Marcelo Pombo, Pablo Suárez y Fabián Burgos.

Estos artistas circulaban por exhibiciones, talleres, premios y residencias, como el Programa de Becas para Artistas Jóvenes de Guillermo Kuitca, Fundación Espigas, la Fundación Banco Patricios, el Taller de Barracas, premios en fundaciones como la de Federico Klemm, Amalia Fortabat, Banco Patricios, Banco Ciudad, entre tantos otros, es decir, todos grandes semilleros 
de artistas contemporáneos de circulación internacional activos hasta la actualidad.

En arteBA, estos artistas comenzaron a participaron de manera cada vez más notoria: Luisa Pedrouzo presentó en 1998 obra de Daniel Ontiveros junto a Cristina Piffer. También se mencionó el caso de Ruth Benzacar, con producciones de Nicola Costantino y Rosana Fuertes, entre otros. Arcimboldo presentó por primera vez en la feria obra de Víctor Florido junto a Benito Laren y Magdalena Jitrik. Se trata de nombres que lograrían notoriedad en la década siguiente, y que siguen resonando como grandes artistas contemporáneos en la actualidad.

Sin embargo, hacia fines de esta década, se les agregarían generaciones más jóvenes, que se comenzarían a mostrar en un espacio común a partir de 2000 bajo la denominación "Nuevas expresiones del arte". Ese es el caso de la galería Gara, que presentó a Fabiana Barreda, Marina De Caro y Raúl Flores, tres artistas de la escena contemporánea de la década que comenzaba y cuyas poéticas la galería definía como experimentales. Además de los artistas mencionados, Gara representaba a Ana López, Marta Ares y Lorena Ventimiglia, y su local estaba ubicado en las cercanías de Juana de Arco, que tendría en su plantel a Julián Terán y Gabriel Baggio, entre otros artistas contemporáneos.

Esto no quiere decir que no se hayan ofrecido producciones de artistas más consagrados: por ejemplo, en 1994 Adriana Indik presentó obra de Carlos Alonso, Claudia Bernardi, Ignacio Colombres, Raquel Forner, César López Claro y Rómulo Macció, mientras que Ruth Benzacar mostró a Luis Fernando Benedit y Lisenberg fue con Luis Barreda, Ricardo Benaím, Juan Carlos Brea, Anahí Cáceres, Wolfgana Fratzscher, Mónica Girón, Julio Hirsch, Joseph Werner, Wolfgang Zelmer, Danilo Danziger. En 1996 se invitó a un grupo de artistas, los Pintores de La Boca, a una exposición especial que fue acompañada en el catálogo por un texto de Albino Diéguez Videla titulado "El tiempo perdido de los pintores de La Boca", que recorre brevemente la presencia de artistas boquenses en la historia del arte argentino. En 2000, Laura Haber llevó a Roberto Aizenberg, Carlos Alonso, Claudia Aranovich, Libero Badii, Juan Batlle Planas, Antonio Berni, Marcelo Bonevardi, Oscar Bony, Ernesto Deira, Jorge De La Vega, Juan Doffo, Roberto Elía, Rómulo Macció, Aldo Paparella, Duilio Pierri, Emilio Pettoruti, Guillermo Roux, Lino Enea Spilimbergo, Joaquín Torres García y Xul Solar.

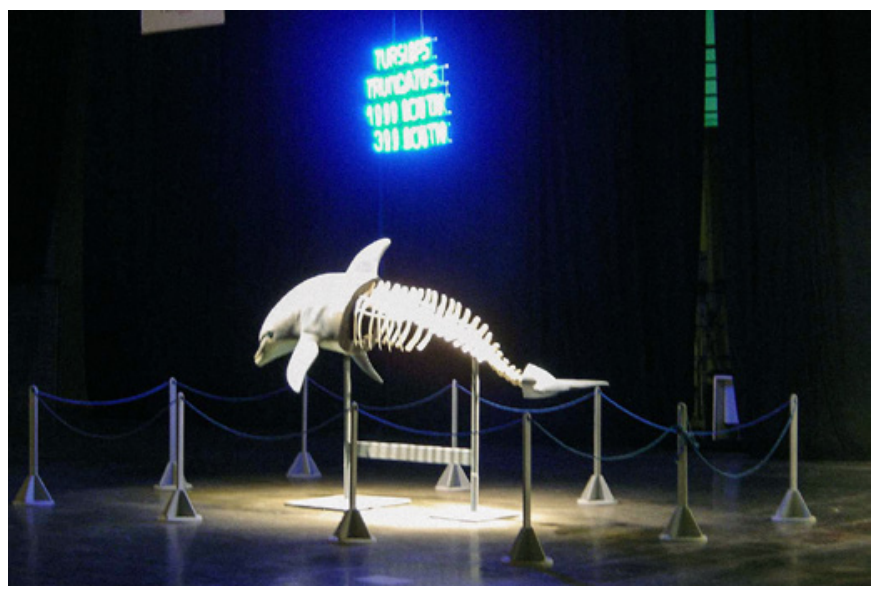

Figura 6. Vista de Open Space en arteBA 2008. "Tursiops Truncatus (Delfín común, Tonina o Delfín Nariz de botella)" (Luis F. Benedit, 2008). Galería Wussmann. Fuente: Archivo Fundación arteBA.

En 2001, se instauró la exposición “Espacio Abierto arteBA - Nuevos espacios, nuevos lenguajes", que estuvo a cargo del crítico Jorge López Anaya. Se trató de un espacio dedicado a seis galerías jóvenes: Belleza y Felicidad, Bis, Duplus, Braga Menéndez, Gara y Sonoridad Amarilla, algunas de las cuales eran de las galerías jóvenes que participaron de la muestra PanoraMIX en PROA el año $2000^{6}$. El proyecto de arteBA se presentó en el texto curatorial de la siguiente manera:

Espacio Abierto está dedicado a las galerías jóvenes que, en los últimos años, comenzaron a apropiarse de territorios artísticos no tradicionales. Se trata de espacios surgidos como alternativa a las galerías tradicionales, generalmente instaladas en los barrios de Retiro y Recoleta. En su conjunto, representan un grupo de interesantes iniciativas personales, pluralistas y abiertas a la búsqueda de los nuevos artistas y de los nuevos lenguajes. El desplazamiento se inició en 1996, cuando se inauguró Gara en Palermo Viejo (López Anaya, 2001, s/p).

\footnotetext{
6 "PanoraMIX" había sido una experiencia de incorporación de propuestas emergentes a la programación de Fundación PROA, como forma de presentar las tendencias del nuevo milenio. Se realizó en 2000 y convocó a artistas de diferentes disciplinas, entre otros, Ernesto Arellano, Fabiana Barreda, Adriana Bustos, Cynthia Cohen, Marina De Caro, Raúl Flores, Nushi Muntaabski, Cecilia Pavón, Pimiento Popp, Ros, Cristina Schiavi y Augusto Zanela (visuales), Fernando Brizuela, Martin Guillot, Ignacio Iasparra, Esteban Pastorino, Hernán Salamanco / Verónica Romano, Rosana Shoijett, Cecilia Szalkowicz, Juan Erlich (fotógrafos) y Leo Battistelli, Juan Cali Mármol, Marta Fuentes, Mónica Jacobo, Alejo Petrucci, José Pizarro, Gaba Sans Sweet, Marcelo Santorelli, Mariano Sardón, Lucrecia Urbano, Marcos Xcella, Pablo Ziccarello, Pared Experimental y Alberto Passolini. (random)
} 


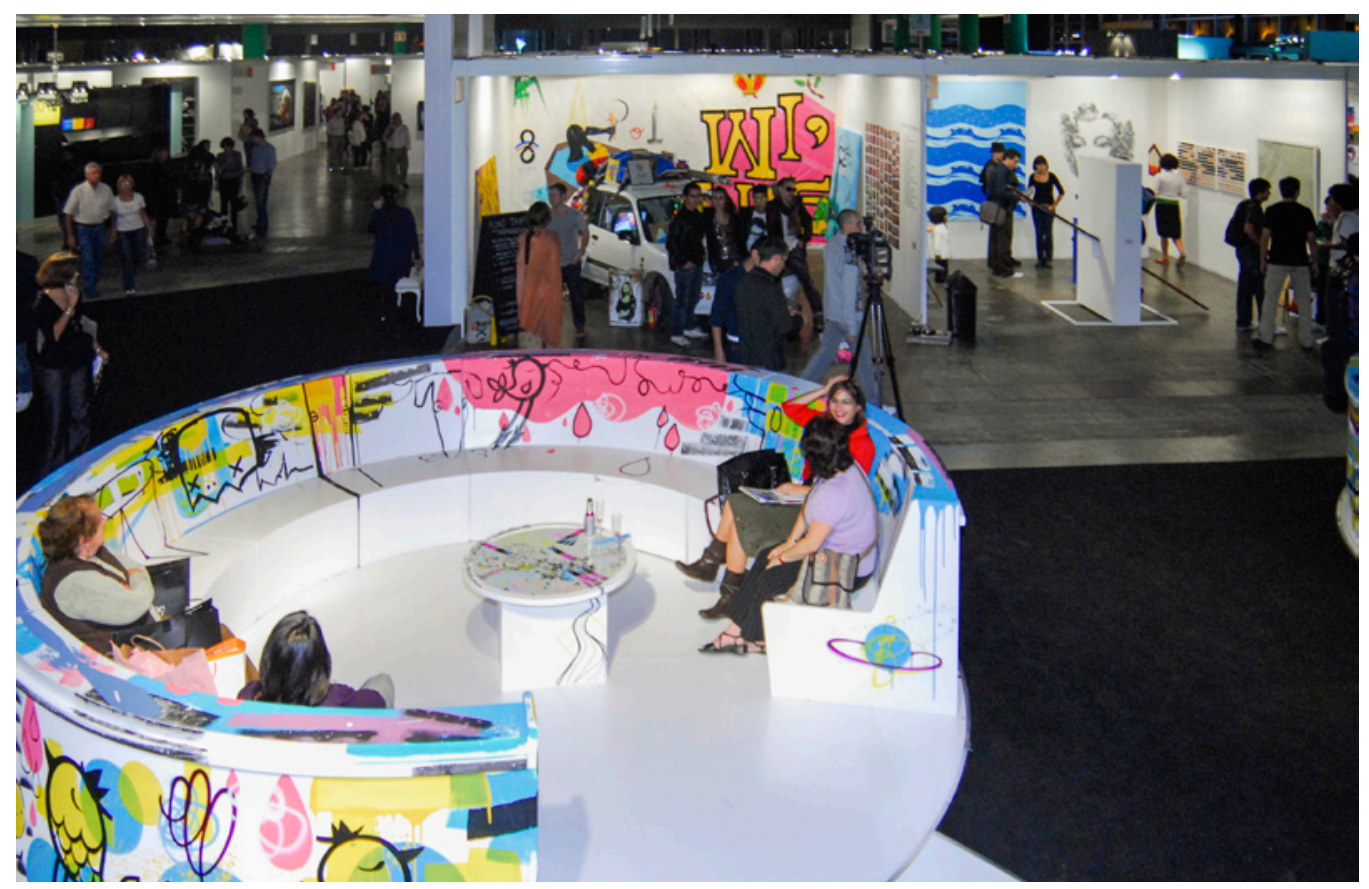

Figura 7. Vista de sección Barrio Joven en arteBA 2009. De izquierda a derecha: galerías Corazón de Bully,

Espacio La Punta y Traffix. Fuente: Archivo Fundación arteBA.

Al año siguiente, esta muestra se transformó en una sección de galerías denominada "Nuevas expresiones del arte" y presentó a MOTP Arte Contemporáneo, Sonoridad Amarilla, Van Riel (que instaló un espacio en la sección principal también), Lelé de Troya, Ruth Benzacar (al igual que Van Riel, presente en ambas secciones), Elsi del Río, Instantes Gráficos, Consorcio de Arte de Buenos Aires, Espacio Vox y Belleza y Felicidad? El reconocimiento de la centralidad de estas galerías autogestionadas en un contexto de crisis profunda en el cual se desintegraban los lazos sociales y, también, se desfinanciaba por completo a las instituciones artísticas oficiales, hace explícito un cambio en la escena local y en las maneras de circulación del arte.

Las propuestas de estas galerías estaban abriendo un panorama de las artes con un sello diferente a la generación de los noventa; estéticas no dominantes sino de existencia sincrónica, temáticas que atraviesan desde problemáticas heterogéneas, desde la experiencia urbana y el consumo y desecho de objetos, hasta

$7 \quad$ Entre los artistas exhibidos, se destacan Ernesto Arellano, Ernesto Ballesteros, Nicola Costantino, Marina De Caro, Sergio De Loof, Carlos Furman, Martín Di Girolamo, Inés Drangosch, Claudia García Lorente, Víctor Grippo, Jorge Gumier Maier, Lola Goldstein, Daniel Herce, Agustín Inchausti, Roberto Jacoby, Alfredo Londaibere, Fernanda Laguna, Benito Laren, Fabián Marcaccio, Alberto Passolini, Marcelo Pombo, Ana Porchilote, Alfredo Prior, Inés Raiteri, Cristian Segura, Guillermo Ueno y Nahuel Vecino. miradas acerca de ciertos procesos de transmisión cultural (Baeza, 2017). El aspecto heterogéneo de la convocatoria invita a pensar su carácter contemporáneo desde el punto de vista de la no dominancia de estilos o relatos (Danto, 2009).

Su introducción en la feria, entonces, significaba una apuesta de ambas partes del contrato: por un lado, la Fundación arteBA elegía abrir un lugar que sería en años posteriores expandido y ocupado por el Barrio Joven y, por otro lado, las galerías y artistas representados se insertaban en un mercado todavía resistente a sus modos de operar.

Esta transformación de arteBA fue también un punto de discusión en la prensa. Por ejemplo, desde Página 12, Fabián Lebenglik comentaba:

“La enunciación de una apuesta por el arte contemporáneo genera al mismo tiempo una puesta al día de los galeristas y un apoyo explícito a los espacios emergentes, que sirven también como estímulo para que los galeristas más establecidos no se detengan en la búsqueda. A medida que la Feria se va auto imponiendo metas más rigurosas, crece el nivel de los stands. Los espacios emergentes funcionan como fuente de acceso a los nuevos artistas y tendencias, pero también 


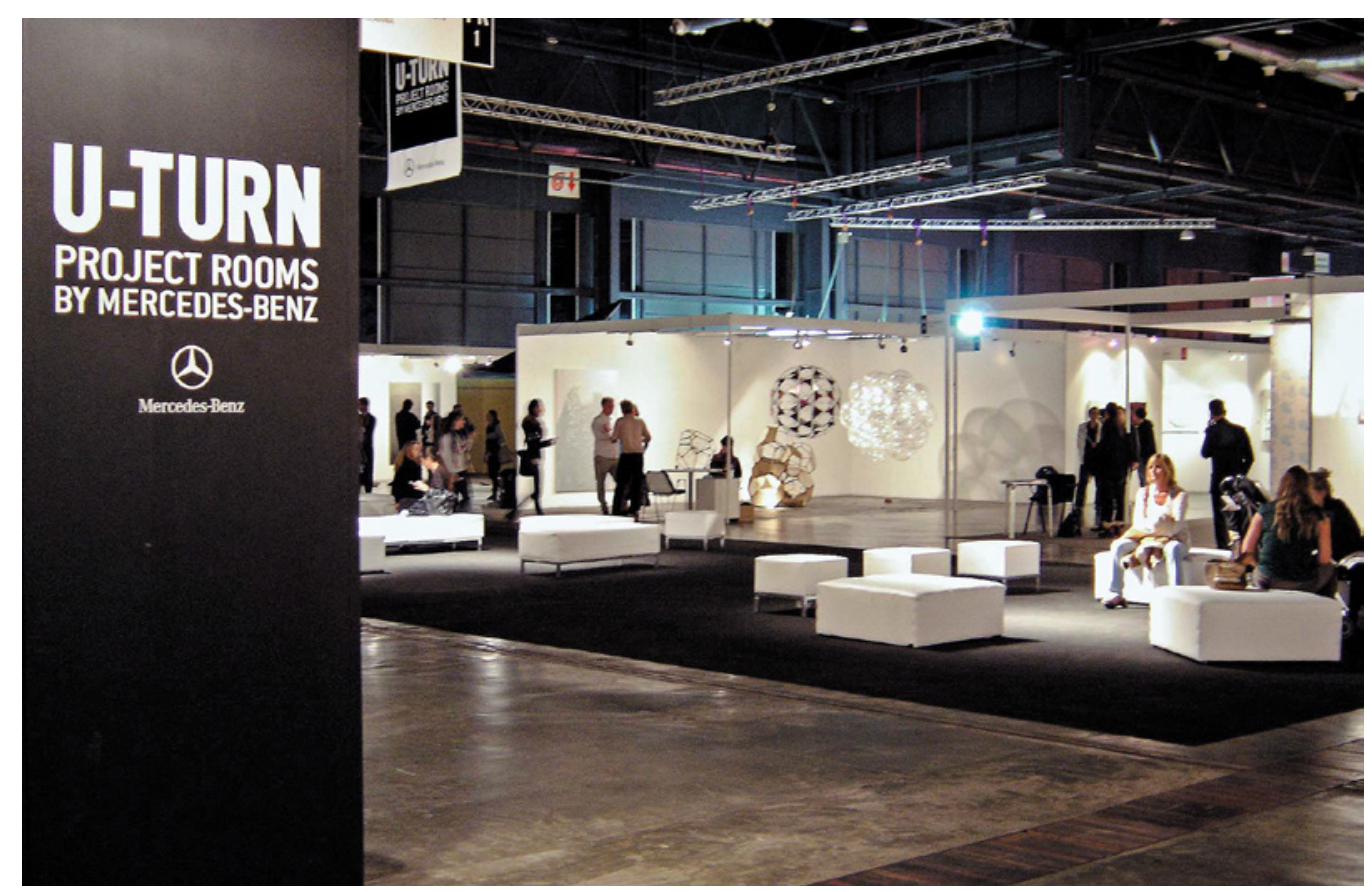

Figura 8. Vista de sección U-Turn en arteBA 2011. "Space elevator/Spark 460" (Tomás Saraceno, 2010) en la galería Andersen's Contemporary. Fuente: Archivo Fundación arteBA.

evidencian una actitud, un modo de colocarse ante el medio y el mercado" (Lebenglik 2003, s/p).

Es destacable la última oración de esta cita, que indica con claridad la finalidad de la enunciación de arteBA como feria de arte contemporáneo. Se trataba de colocarse en una posición determinada frente a la escena y frente al mercado. Esta estrategia, como se afirmó anteriormente, incluyó un progresivo despojamiento de espacios feriales para dar paso a más metros cuadrados destinados a proyectos especiales con curadurías externas y otros instrumentos propios del modo de circulación imperante a nivel internacional.

Otro cambio importante en cuanto a la propuesta de galerías y artistas emergentes lo constituyó la creación del Barrio Joven, en 2005. Al igual que las "Nuevas Expresiones del Arte", Barrio Joven tuvo por objetivo canalizar las producciones y galerías emergentes en un mismo sector, de modo tal que la espacialidad de arteBA se dividió en secciones.

La idea de otorgar espacios a menor costo y por un período determinado a galerías nuevas también permitía una sectorización del arte contemporáneo emergente como estrategia de presentación a compradores locales e internacionales:
"Sobre eso se abrió. También la feria tenía que tener distintos puntos geográficos de atracción: si queres recorrer una determinada área debías ir para un lado, cosa que te obligaba a recorrer la feria entera. Si bien había galerías jóvenes o emergentes con espacios propios, se crea el Barrio Joven con su propio espacio de circulación, verificación y análisis, para que tuvieran un costo menor de ingreso y poder generar desde ese lugar". ${ }^{8}$

Además del propósito de circulación propia como punto de referencia para quienes estaban interesados en este tipo de producciones, había una necesidad de favorecer las compras, y la estrategia de inserción del arte emergente servía también a esos efectos. Las galerías participantes del Barrio Joven eventualmente (luego de tres años) podían ser seleccionadas para exponer en la sección principal, de manera que se habilitaba un recambio en la sección de espacios emergentes y, simultáneamente, se favorecía un camino de relativa legitimación rápidamente.

En principio, se le otorgaba más importancia a las operaciones curatoriales de selección y espacialización que a las obras exhibidas, lo cual es curioso pero sigue un criterio similar al expresado para la sección principal en 


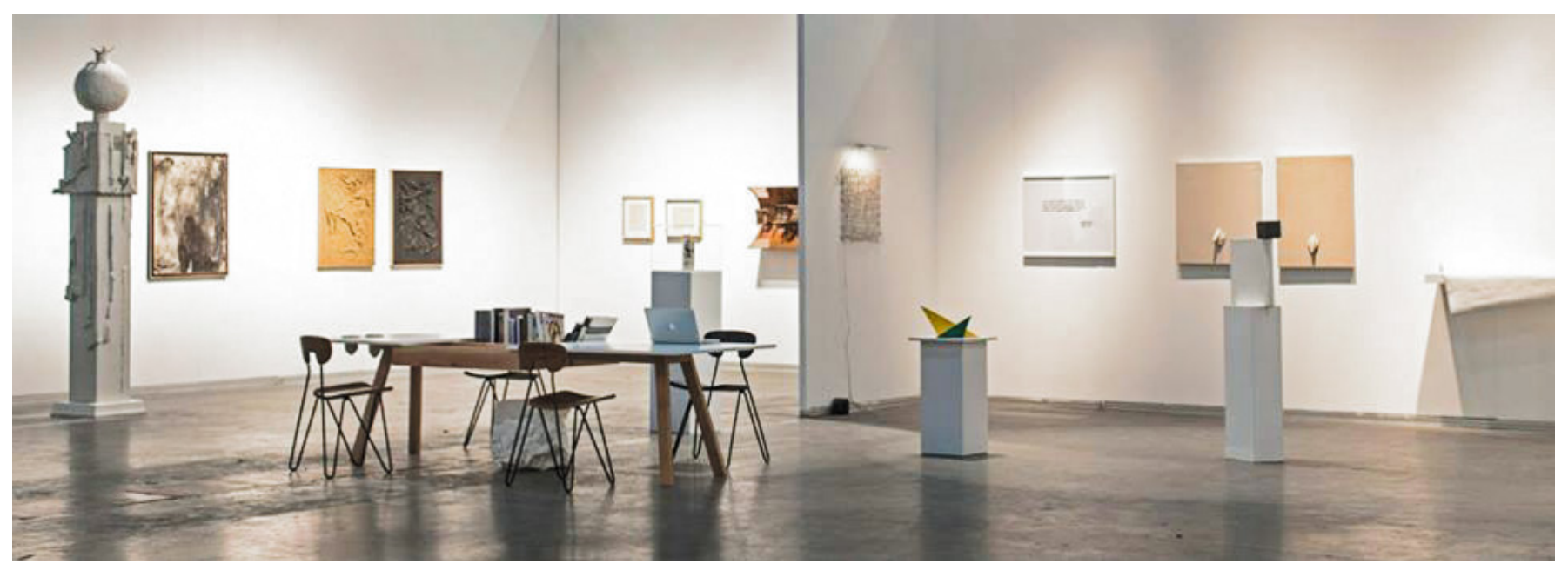

Fiugra 9. Vista de sección Cabinet en arteBA 2014. Stand de Cosmocosa con obras de Eduardo Costa. Fuente: Archivo Fundación arteBA.

cuanto a que arteBA no decide qué expone cada galería sino qué galerías exponen, según aseguró Fiterman en entrevista. ${ }^{9}$ También es notorio el primer objetivo, de federalización, que se relaciona con aquellas propuestas que se realizaban en ediciones anteriores en torno a la incorporación de jóvenes artistas del interior (20 artistas del interior fue una muestra que se repitió desde 1994 hasta 1997, por ejemplo).

En su primera edición, las galerías seleccionadas fueron: Baltar, Belleza y Felicidad, Boquitas Pintadas, Centro Cultural Casa Da Ribeira, Club del Dibujo, Espacio Vox, Estudio 13, Juana de Arco, La Baulera, MOTP, Sonoridad amarilla — Jinetes azules y Viajo. Es decir, algunas galerías como Espacio Vox, Juana de Arco, Sonoridad Amarilla o MOTP ya habían participado de la sección "Nuevas Expresiones..." que fue el prototipo del Barrio Joven, y en otros casos eran primeras participaciones.

Por otra parte, los artistas exhibidos fueron un mix entre algunos con algo más de trayectoria como Baggio, Larrambebere, Scafati (que de hecho ya habían participado de ediciones de arteBA) y otros más emergentes como Del Río, Villar Rojas o Zukerfeld, entre muchos. Al año siguiente el Barrio Joven incluiría a galerías nuevas como Appetite, Jardín Oculto, Trastienda en Bruto y Trip, Centro Rodante de Experimentación y Exhibición de Arte.

9 Jacobo Fiterman, entrevista personal, Buenos Aires, 9 de abril de 2019.
Nuevamente, algunos nombres serían repetidos en otras entregas de arteBA y tendrían notoriedad en la escena en general, como Aráoz, Bonadeo, Brizuela, Florido, Iriart, Galindo, Legón, Szalkowicz y otros. En los años venideros se sumarían otras galerías y artistas (por ejemplo, en 2007 se presentó Rosa Chancho (dirigida por Julieta García Vázquez, Mumi, Javier Villa, Tomás Lerner y Osías Yanov) y Espacio Radio Libertad de Chaco, entre otros proyectos nacionales y extranjeros.

En 2008 se agregaron otras como Elsa One (dirigida por Marina De Caro y María Julia Iglesias), la peruana Revólver y Sapo. En 2009 se pudo ver el estand de Espacio La Punta y Júpiter. En 2010 se agregaron Cobra, Miau Miau y Mite.

A partir de 2011, el Barrio Joven se comienza a anunciar, desde los catálogos y la web de arteBA, ya no como una exposición "especial" como hasta ese momento, sino como una sección más de expositores (es decir, de alguna manera, elevando su estatus a uno similar al de la sección principal, pero de galerías emergentes). Este movimiento retórico es importante debido a que da cuenta de un cambio de orientación en la consideración de los espacios de arte joven, en tanto que se convierten en una parte más de la feria, y ya no como un lugar especial que fue, al igual que "Open Space", "U-Turn" o "Dixit". Algunas de las galerías nacionales que participaron del Barrio Joven a partir de 2011 son Big Sur (que exhibió obras de Paula Duró, Maricel Nowacki, Sofía Reynal, Nicolás Sarmiento y Mara Tacón) y Rayo Lazer (que llevó trabajos de Jesica Bianchi, Franco Ferrari, Juan Matías Killian, Martín Osuna, Nicolás Ozuna, Lucio Romano, Nicolás Sarmiento 
y Mario Scorzelli), El Rancho, Isla Flotante y Ruby, El Mirador, Galería Inmigrante, Hache, Otero y Pasto.

Finalmente, en 2016 se vieron por primera vez El Gran Vidrio, con trabajos de Carla Barbero, Luciano Burba y Angel Pacheco; Hilo, con obra de Camila Lamarca y Dayana Santiago; y UV Studios, que llevó producciones de Básica TV, Federico Cantini y Lolo y Lauti.

Es decir que, en principio, la construcción de lo contemporáneo en arteBA tiene como soportes tanto la participación de artistas, como la propuesta de las galerías y los proyectos especiales. En este sentido, la coexistencia entre ofertas de poéticas más tradicionales con propuestas más emergentes cumple con aquella multiplicidad temporal y utilización de las imágenes del pasado para la construcción de diferentes relaciones con el presente que anuncian autores como Smith y Didi Huberman. La estrategia da cuenta del funcionamiento reticular del campo de las artes en tanto que las agencias de curadores, historiadores, galeristas, coleccionistas, etc. se combinan para construir un sistema de valoración que se traduce indefectiblemente en los precios y que logra posicionar al mercado como un factor relevante a la hora de tasar obras y artistas. Esta manera de actuación conjunta y retroalimentativa fue identificada, por su escala y expansión a partir de la caída del muro de Berlín, como característica del arte contemporáneo (Moulin, 2012, Graw, 2013).

\section{Reflexiones}

Si se toman en cuenta las estrategias desplegadas por arteBA (incorporación de artistas emergentes, ampliación de los espacios destinados a proyectos especiales y con curaduría específica, invitación a profesionales y coleccionistas nacionales e internacionales, entre otras), se puede hablar de un aprovechamiento del sistema de retroalimentación para posicionar a arteBA como una feria modelo de contemporaneidad en Latinoamérica.

Este aspecto, que se profundiza a partir de 2003 cuando se cambió la denominación a "feria de arte contemporáneo" estuvo presente desde su creación, al menos en cuanto a la exhibición de artistas de circulación por otros espacios y de la institución de espacios diferenciados de la oferta de galerías. Tal vez la diferencia radica en la escala del propósito de "contemporaneizar" arteBA para ponerla en el mapa global del arte. En este sentido, se vale de las definiciones de arte contemporáneo que lo sitúan como el arte sin relatos unificadores y de una visión comercial que se basa en el lugar del mercado como legitimador de tendencias, en especial las emergentes.

El modelo de arteBA se configura a partir de uno hegemónico en tanto da cuenta de los elementos y tácticas que componen los circuitos globales y, al mismo tiempo,

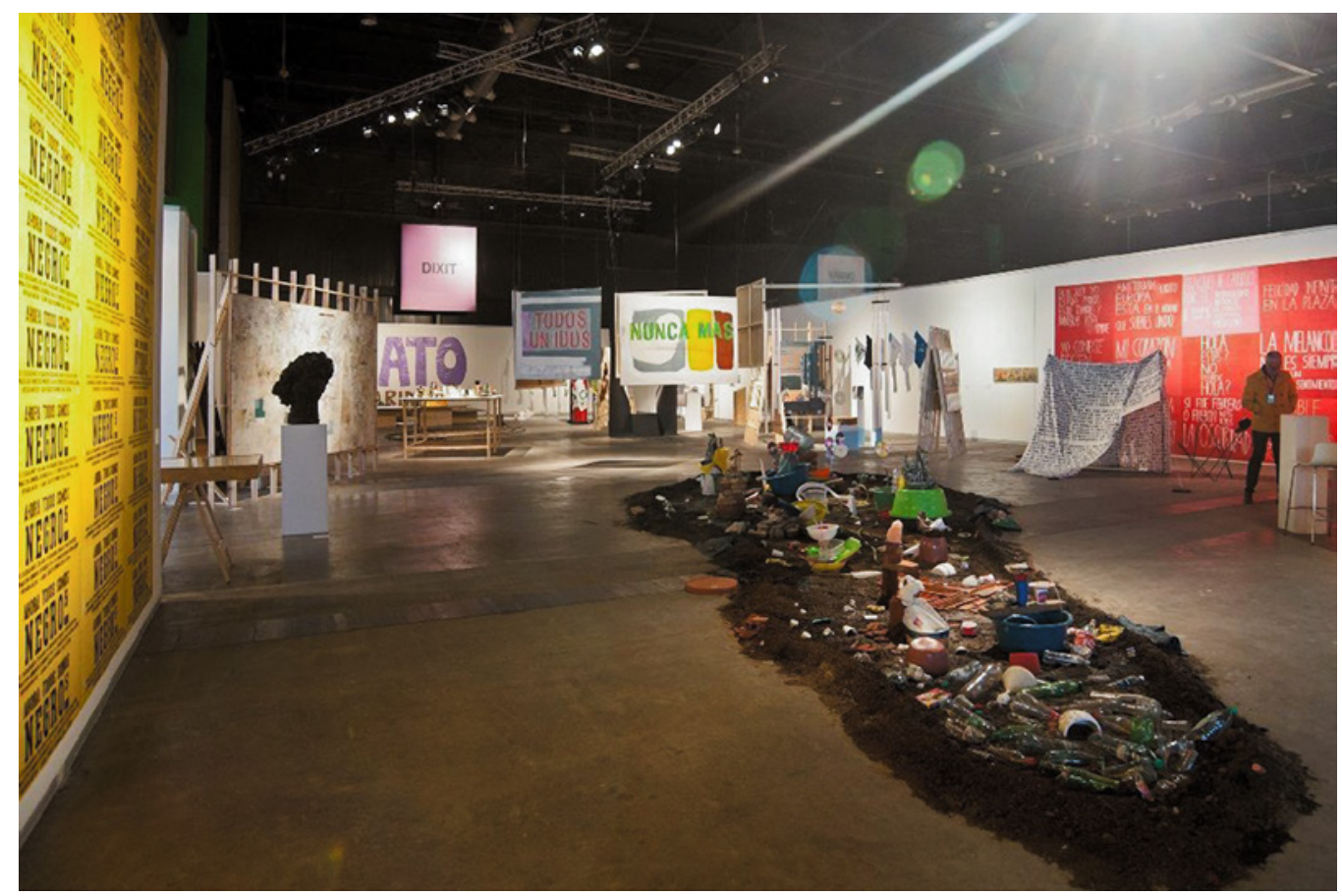

Figura 10. Vista de sección Dixit en arteBA 2016. Exhibición "Oasis", curaduría de Federico Baeza, Lara Mármor y Sebastián Vidal Mackinson. Edición 25 aniversario arteBA. Fuente: Archivo Fundación arteBA. 
acude al internacionalismo como modo de legitimarse: se mencionan la cantidad de galerías extranjeras participantes, se destacan las invitaciones a profesionales europeos y estadounidenses, se produce el programa VIP para que coleccionistas del mundo recorran la feria y galerías de Buenos Aires para perfilar a los artistas más jóvenes y emergentes a nivel internacional, se instaura el programa de adquisiciones a museos para incrementar sus colecciones a partir de una unión público-privada, entre otros métodos.

La imagen que arteBA crea de la contemporaneidad es dominante también en tanto está compuesta por esta misma reticularidad retroalimentativa que refleja, y por lo tanto lo que muestra y produce (exhibiciones, publicaciones, por ejemplo) da cuenta de ese modelo global. Dos salidas posibles fueron las ediciones de "Dixit" de 2014 y 2016, en las que se identificaron modelos de contemporaneidad ligados a lo regional y que proponían la incorporación de lecturas alternativas. Entonces, si bien la enunciación de la contemporaneidad como estrategia comercial es explícita, también se puede observar que la feria se definió como una instancia de discusión de ciertas representaciones identitarias acerca del arte latinoamericano.

En este sentido, es destacable que la especificidad regional y local de arteBA pueda ofrecer puntos de fuga a una estrategia de inserción contemporánea bajo parámetros hegemónicos, que tomen en cuenta las modificaciones que se produjeron a las nociones de centro y periferia, a la visión de un "otro" en las artes, y a la propia definición de lo latinoamericano, como proponen autores como Ticio Escobar (1997) para dar cuenta de la globalidad como un espacio rizomático de lo plural —una mirada que se presenta al mismo tiempo optimista y resignada respecto de los avances de lo regional en las cartografías del arte contemporáneo global y las hibridaciones culturales e identitarias generadas por la escala de los circuitos inter y transnacionales sobre lo local o regional.

Para el autor, el carácter desterritorializado del arte contemporáneo es limitado pues "Gran parte de la producción artística sigue condicionada por coordenadas territoriales..." (Escobar, 1997, p. 29). Sin embargo, su visión reconoce también las tensiones entre lo global y lo regional como un ámbito de posibilidad, de potencialidad para el cambio. En arteBA eso tiene atisbos de aparición en, por ejemplo, las dos ediciones de "Dixit" presentadas, pero también en ciertas zonas del aparato paracuratorial. Sin embargo, son salidas dispersas y con horizontes limitados. A razón de ello, deja espacio para investigar en trabajos futuros la complejidad del nexo que une la localidad con la globalidad en la feria.

\section{Referencias}

Alberro, A. (Ed.) (2011). ¿Qué es arte contemporáneo hoy? Simposio Internacional. Pamplona: Universidad Nacional de Navarra.

Bishop, C. (2018). Museología radical O iqué es 'contemporáneo' en los museos de arte contemporáneo? Buenos Aires: Libretto.

Baeza, F. (2017). Proximidad y distancia. Arte y vida cotidiana en la escena argentina de los 2000. Buenos Aires: Biblos.

Danto, A. (2009). Después del fin del arte: el arte contemporáneo y el linde de la historia. Buenos Aires: Paidós.

Didi Huberman, G. (2014). Lo que vemos, lo que nos mira. Buenos Aires: Manantial.

Escobar, T. (1997) "Arte latinoamericano: el debe y el haber de lo global", en El arte en los tiempos globales. Tres textos sobre arte latinoamericano. La Asunción: Don Bosco/Ñanduti Vive, pp. 45-67.

Fundación arteBA (2004). Catálogo de la feria de arte contemporáneo arteBA 04. Buenos Aires: arteBA.

Giunta, A. (2014). ¿Cuándo empieza el arte contemporáneo? Buenos Aires: Fundación arteBA.

Graw, I. (2013). ¿Cuánto vale el arte? Mercado, especulación y cultura de la celebridad. Buenos Aires: Mar Dulce.

Groys, B. (2009). "Comrades of Time", efflux jornal, 11, pp. 1-11. Disponible en https://tinyurl.com/4hsaje2m (Consulta realizada 26/02/2021). (2014). Volverse público. Las transformaciones en el arte en el ágora contemporánea. Buenos Aires: Caja Negra.

Lebenglik, F. (2003). "La Feria viene con novedades", Pagina 12 Plástica, 17 de junio. Disponible en 
https://tinyurl.com/5ynrv4wh (Consulta realizada

26/02/2021).

López Anaya, J. (2001). "Espacio Abierto", en AAVV,

Catálogo arteBA 2001, Buenos Aires: Fundación arteBA,

$\mathrm{s} / \mathrm{p}$.

Martinez Quijano, A. (2011). “Confían en que apertura de arteBA active el mercado", Ámbito Financiero, 19 de mayo. Disponible en https://tinyurl.com/y2zaacdr (Consulta realizada 26/02/2021).

Millan Valdes, R. (2009). "Sistema global del arte: museos de arte contemporáneo, bienales y ferias como mecanismos de posicionamiento urbano en los circuitos globales de intercambio", Revista Eure, 35 (106), pp. 155-169. DOI: http://dx.doi.org/10.4067/ S0250-71612009000300008.

Moulin, R. (2012). El mercado del arte. Mundialización y nuevas tecnologías. Buenos Aires: la marca editora.

Ramírez, M. C. (1996) "Brokering Identities" en Greenberg, Reesa, Ferguson, Bruce, Nairne, Sandy (eds.) Thinking about exhibitions. London and New York: Routledge, 1996, pp. 21-38.

Sassatelli, M. (2016). "The biennalization of art worlds: the culture of cultural events", en Laurie Hanquinet y Michael Savage (Eds.), Routledge International Handbook of Art and Culture. Nueva York: Routledge, pp. 277-289.

Smith, T. (2012). ¿Qué es el arte contemporáneo? Buenos Aires: Siglo XXI Editores.

Staniszewski, M. A. (2001). The Power of display. A history of exhibition installations at the Museum of Modern Art. Massachusetts: The MIT Press. 